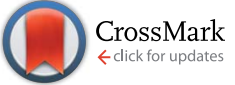

Cite this: RSC Adv., 2017, 7, 7610

\title{
Role of $\mathrm{Tf}_{2} \mathrm{~N}^{-}$anions in the ionic liquid-water distribution of europium(III) chelates $\uparrow$
}

\author{
Hiroyuki Okamura, ${ }^{\text {*a }}$ Noboru Aoyagi, ${ }^{\mathrm{b}}$ Kojiro Shimojo, ${ }^{a}$ Hirochika Naganawa ${ }^{a}$ \\ and Hisanori Imura*c
}

The role of bis(trifluoromethanesulfonyl)imide $\left(\mathrm{Tf}_{2} \mathrm{~N}^{-}\right)$anions in the ionic liquid-water distribution systems of Eu(III) chelates with 2-thenoyltrifluoroacetone ( $\mathrm{Htta}$ ) was investigated by liquid-liquid distribution and time-resolved laser-induced fluorescence spectroscopy (TRLFS). The extraction constants of neutral $\mathrm{Eu}(\mathrm{tta})_{3}$ and anionic $\mathrm{Eu}(\mathrm{tta})_{4}{ }^{-}$chelates in 1-alkyl-3-methylimidazolium bis(trifluoromethanesulfonyl)imide ([ $\mathrm{C}_{n}$ mim] $\left[\mathrm{Tf}_{2} \mathrm{~N}\right]$ ) were determined by analyzing the distribution equilibrium. The effect of the ionic liquids on the distribution constant of the neutral $\mathrm{Eu}(\mathrm{tta})_{3}$ chelate was evaluated by the regular solution theory. The distribution constant of Eu(tta) $)_{3}$ in $\left[\mathrm{C}_{n}\right.$ mim] $\left[\mathrm{Tf}_{2} \mathrm{~N}\right]$ was increased dramatically by the solvation effects of Eu(tta) $)_{3}$ in $\left[\mathrm{C}_{n}\right.$ mim] $\left[\mathrm{Tf}_{2} \mathrm{~N}\right]$. TRLFS for $\left[\mathrm{Eu}(\mathrm{tta})_{3}\left(\mathrm{H}_{2} \mathrm{O}\right)_{3}\right]$ synthesized revealed that the $\mathrm{Eu}(\mathrm{tta})_{3}$ chelate was almost completely dehydrated in a series of $\left[\mathrm{C}_{n} \operatorname{mim}\right]\left[\mathrm{Tf}_{2} \mathrm{~N}\right](n=2-10)$. The Eu(tta)$)_{3}$ chelate exists as dior tri-hydrates in 1-ethyl-3-methylimidazolium perchlorate $\left(\left[\mathrm{C}_{2} \mathrm{mim}\right]\left[\mathrm{ClO}_{4}\right]\right)$ containing $20 \mathrm{~mol} \mathrm{dm}^{-3}$ water, whereas mono-hydrated chelate was formed in $\left[\mathrm{C}_{2} \mathrm{mim}\right]\left[\mathrm{Tf}_{2} \mathrm{~N}, \mathrm{ClO}_{4}\right]$ in the presence of $0.50 \mathrm{~mol}$ $\mathrm{dm}^{-3} \mathrm{Tf}_{2} \mathrm{~N}^{-}$and $20 \mathrm{~mol} \mathrm{dm}{ }^{-3}$ water. These results show that the coordinated water molecules of $\left[\mathrm{Eu}(\mathrm{tta})_{3}\left(\mathrm{H}_{2} \mathrm{O}\right)_{3}\right]$ were replaced by the $\mathrm{Tf}_{2} \mathrm{~N}^{-}$anions. In fact, an anionic adduct, $\left[\mathrm{Eu}(\mathrm{tta})_{3}\left(\mathrm{Tf}_{2} \mathrm{~N}\right)\right]^{-}$, was observed by electrospray ionization mass spectrometry in the presence of $\left[\mathrm{C}_{4} \operatorname{mim}\right]\left[\mathrm{Tf}_{2} \mathrm{~N}\right]$.

Received 23rd November 2016
Accepted 9th January 2017

DOI: $10.1039 / c 6 r a 27208 h$

www.rsc.org/advances also positively or negatively charged species can be extracted into the IL by ion exchange via the cationic or anionic constituent of the ILs. ${ }^{20-22}$ These unique mechanisms in an IL system often lead to an enhancement in the extractability of a particular metal ion. However, when the extracted ionic species becomes a part of the IL, it is generally difficult to recover metal ions extracted into the IL phase. Acidic chelating reagents such as $\beta$-diketones can potentially overcome these problems. ${ }^{23-31}$ Although it has been found that IL distribution systems for neutral complexes also exhibit high extraction performance compared with conventional organic solvent systems, the cause of the extraction enhancement except the ion-exchange mechanism $^{23}$ has yet to be clarified. Therefore, in-depth systematic studies on IL distribution systems of metal chelates are required.

Time-resolved laser-induced fluorescence spectroscopy (TRLFS) has been widely used as an analytical technique for the speciation of fluorescent metal ions such as lanthanides(III) and actinides(III). ${ }^{32-39}$ Because the fluorescence is sensitive to the inner-sphere coordination environment of the metal ion, the fluorescence intensity, spectral shape, and fluorescence lifetime change are dependent on the solvation or coordination structure of the metal chelate. Especially, the fluorescence lifetime, $\tau$, gives the hydration state in the first coordination sphere of the metal ion. Stumpf et al. reported on the solvation of the Euperchlorate and -triflate salts and the ligand exchange reaction in 1-butyl-3-methylimidazolium bis(trifluoromethanesulfonyl) 
imide $\left(\left[\mathrm{C}_{4} \mathrm{mim}\right]\left[\mathrm{Tf}_{2} \mathrm{~N}\right]\right)$ by TRLFS. ${ }^{32}$ The hydration properties of $\mathrm{Eu}\left(\mathrm{Tf}_{2} \mathrm{~N}\right)_{3}$ in $\mathrm{Tf}_{2} \mathrm{~N}$-based IL were reported by Brandner et al., indicating that the added water in the solution binds quantitatively to Eu(III) ion. ${ }^{35}$ Furthermore, Ansari et al. reported that the complexation of $\operatorname{Ln}\left(\mathrm{Tf}_{2} \mathrm{~N}\right)_{3}(\mathrm{Ln}=$ lanthanides $)$ with nitrate in wet $\left[\mathrm{C}_{4} \mathrm{mim}\right]\left[\mathrm{Tf}_{2} \mathrm{~N}\right]$ proceeds via the replacement of water molecules from the inner solvation spheres of $\operatorname{Ln}(\mathrm{III})$ ions. ${ }^{37,38}$ The coordination environment of $\operatorname{Ln}(\mathrm{III})$ ion in ILs was well studied, ${ }^{40}$ whereas the interaction between hydrophobic lanthanide chelates and other potential ligands such as water, halide ions, and IL components in ILs has seldom been documented.

The number of coordinated water molecules $\left(n_{\mathrm{H}_{2} \mathrm{O}}\right)$ of the central Eu(III) ion in various complexes can be estimated by the following equation: ${ }^{41}$

$$
n_{\mathrm{H}_{2} \mathrm{O}}=1.05\left(k_{\mathrm{H}_{2} \mathrm{O}}-k_{\mathrm{D}_{2} \mathrm{O}}\right)
$$

where $k_{\mathrm{H}_{2} \mathrm{O}}$ and $k_{\mathrm{D}_{2} \mathrm{O}}(k=1 / \tau)$ are the fluorescence decay constants in $\mathrm{H}_{2} \mathrm{O}$ - and $\mathrm{D}_{2} \mathrm{O}$-containing solvents, respectively. The uncertainty in the calculated values of $n_{\mathrm{H}_{2} \mathrm{O}}$ is approximately \pm 0.5 . Although modified equations having uncertainties $<0.5$ have been reported, ${ }^{42}$ those equations include contributions to quenching from bulk water outside the first coordination sphere. ${ }^{35}$ The calculation method for eqn (1) is appropriate for evaluating the first coordination sphere of $\mathrm{Eu}(\mathrm{III})$ ions in the IL and organic solutions.

Recently, one of the present authors studied the distribution of 2-thenoyltrifluoroacetone (Htta) and its nickel(II) and copper(II) chelates between the 1-alkyl-3-methylimidazolium bis(trifluoromethanesulfonyl)imide $\left(\left[\mathrm{C}_{n} \mathrm{mim}\right]\left[\mathrm{Tf}_{2} \mathrm{~N}\right]\right.$; Fig. 1) phase and the aqueous phase to clarify the specific solvent effect of ILs. ${ }^{27}$ The values of the distribution constants of the neutral metal chelates in IL systems were evaluated on the basis of the regular solution theory. Additionally, the present authors have found the solvation of the neutral Eu(III)-tta chelate $\left(\mathrm{Eu}(\mathrm{tta})_{3}\right)$ in $\left[\mathrm{C}_{4} \mathrm{mim}\right]\left[\mathrm{Tf}_{2} \mathrm{~N}\right]$ by TRLFS and infrared absorption spectroscopy, and proposed specific solutesolvent interactions between the $\mathrm{Eu}(\mathrm{III})$ chelate and $\left[\mathrm{C}_{4} \mathrm{mim}\right]$ $\left[\mathrm{Tf}_{2} \mathrm{~N}\right]{ }^{28}$

$$
\begin{aligned}
& \mathrm{H}_{3} \mathrm{C}-\mathrm{C}_{2} \\
& \mathrm{C}_{2} \operatorname{mim}^{+}(n=2) \quad \mathrm{C}_{4} \mathrm{mim}^{+}(n=4) \\
& \mathrm{H}_{3} \mathrm{C} \\
& \mathrm{C}_{6} \operatorname{mim}^{+}(n=6) \quad \mathrm{C}_{8} \mathrm{mim}^{+}(n=8) \\
& \mathrm{H}_{3} \mathrm{C}-\mathrm{C}_{10} \mathrm{H}_{21} \\
& \mathrm{C}_{10} \mathrm{mim}^{+}(n=10) \quad \mathrm{C}_{4} \mathrm{dmim}^{+}
\end{aligned}
$$

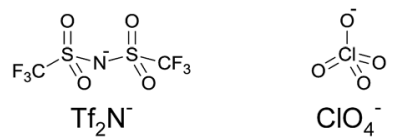

Fig. 1 Chemical structures of ionic liquids employed in this study.
In the present study, the extraction constants for both neutral and anionic Eu(III) chelates with Htta in the [ $\left.\mathrm{C}_{n} \mathrm{mim}\right]$ $\left[\mathrm{Tf}_{2} \mathrm{~N}\right]$ systems where $n=6$ and 8 were determined by analyzing the distribution equilibrium. The effect of the ILs on the distribution constant of $\mathrm{Eu}(\mathrm{tta})_{3}\left(K_{\mathrm{D}, \mathrm{M}}\right)$ was evaluated with the aid of the regular solution theory using the two-phase stability constant of the chelate $\left(K_{\mathrm{D}, \mathrm{M}} \beta_{3}\right)$. The hydration state in the first coordination sphere of $\mathrm{Eu}(\mathrm{tta})_{3}$ in a series of $\left[\mathrm{C}_{n} \mathrm{mim}\right]\left[\mathrm{Tf}_{2} \mathrm{~N}\right](n=$ 2-10) and in an organic solvent containing different concentrations of $\left[\mathrm{C}_{4} \mathrm{mim}\right]\left[\mathrm{Tf}_{2} \mathrm{~N}\right]$ was examined by TRLFS. Furthermore, the effect of the water and $\mathrm{Tf}_{2} \mathrm{~N}^{-}$concentrations on the hydration of $\mathrm{Eu}(\mathrm{tta})_{3}$ in $\left[\mathrm{C}_{2} \mathrm{mim}\right]\left[\mathrm{Tf}_{2} \mathrm{~N}, \mathrm{ClO}_{4}\right]$ (mixed solvent of $\left[\mathrm{C}_{2} \mathrm{mim}\right]\left[\mathrm{Tf}_{2} \mathrm{~N}\right]$ with 1-ethyl-3-methylimidazolium perchlorate, $\left[\mathrm{C}_{2} \mathrm{mim}\right]\left[\mathrm{ClO}_{4}\right]$; Fig. 1) was investigated to clarify the role of the $\mathrm{Tf}_{2} \mathrm{~N}^{-}$anions in the IL-water distribution system. A stable solvated species of the $\mathrm{Eu}(\mathrm{III})$ chelate in the presence of $\left[\mathrm{C}_{4} \mathrm{mim}\right]$ $\left[\mathrm{Tf}_{2} \mathrm{~N}\right]$ was measured by electrospray ionization mass spectrometry (ESI-MS).

\section{Experimental}

\section{Reagents}

The ILs, $\left[\mathrm{C}_{n} \mathrm{mim}\right]\left[\mathrm{Tf}_{2} \mathrm{~N}\right](n=2,4,6,8$, and 10) and 1-butyl-2,3dimethylimidazolium bis(trifluoromethanesulfonyl)imide $\left(\left[\mathrm{C}_{4} \mathrm{dmim}\right]\left[\mathrm{Tf}_{2} \mathrm{~N}\right]\right)$, were synthesized and purified in the same manner as described previously. ${ }^{28}$ The hydrophilic IL, [C $\left.{ }_{2} \mathrm{mim}\right]$ $\left[\mathrm{ClO}_{4}\right]$, was synthesized from 1-ethyl-3-methylimidazolium ethyl sulfate and lithium perchlorate according to the published procedure. ${ }^{43}$ An acidic chelating reagent, Htta, was obtained from Dojindo Laboratories (Japan, 98\% purity), and was used without further purification. A hydrated Eu(III) chelate, $\left[\mathrm{Eu}(\mathrm{tta})_{3}\left(\mathrm{H}_{2} \mathrm{O}\right)_{3}\right]$, was synthesized according to the published method. ${ }^{44}$ Yield $26.9 \%$. Anal. calc. for $\mathrm{EuC}_{24} \mathrm{H}_{18} \mathrm{~F}_{9^{-}}$ $\mathrm{S}_{3} \mathrm{O}_{9}: \mathrm{Eu}, 17.48 ; \mathrm{C}, 33.15 ; \mathrm{H}, 2.09 ; \mathrm{N}, 0.00$. Found: $\mathrm{Eu}, 17.18 ; \mathrm{C}$, $33.48 ; \mathrm{H}, 2.09 ; \mathrm{N}, 0.00 \%$. Three water molecules in the hydrated complex were confirmed by Karl Fischer titration in anhydrous toluene. All other chemicals used were of analytical or guaranteed reagent grade, and were used as received. High purity deionized water $(18.2 \mathrm{M} \Omega \mathrm{cm})$ was used throughout this study.

\section{Distribution procedure}

An aliquot of an aqueous solution containing $1.0 \times 10^{-4} \mathrm{~mol}$ $\mathrm{dm}^{-3} \mathrm{Eu}(\mathrm{III}), 1.0 \times 10^{-1} \mathrm{~mol} \mathrm{dm}{ }^{-3} \mathrm{LiCl}$, and $1.0 \times 10^{-2} \mathrm{~mol}$ $\mathrm{dm}^{-3}$ acetate buffer was shaken for 30-90 min with a $\left[\mathrm{C}_{n} \mathrm{mim}\right]$ $\left[\mathrm{Tf}_{2} \mathrm{~N}\right]$ solution containing $1.0 \times 10^{-3}$ to $1.6 \times 10^{-2} \mathrm{~mol} \mathrm{dm}^{-3}$ $\mathrm{Htta}$ at $25 \pm 1{ }^{\circ} \mathrm{C}$. After phase separation by centrifugation (5000 rpm), the equilibrium $\mathrm{pH}$ value in the aqueous phase was measured. The Eu(III) concentration in the aqueous phase was determined by inductively coupled plasma mass spectrometry (Hewlett Packard HP 4500 or PerkinElmer NexION $300 \mathrm{X})$. The $\mathrm{Eu}(\mathrm{III})$ concentration in the $\left[\mathrm{C}_{n} \mathrm{mim}\right]\left[\mathrm{Tf}_{2} \mathrm{~N}\right]$ phase was determined in the same manner after backextraction with $1 \mathrm{~mol} \mathrm{dm}^{-3} \mathrm{HNO}_{3}$. The distribution ratio $(D)$ of $\mathrm{Eu}(\mathrm{III})$ was calculated from the $\mathrm{Eu}(\mathrm{III})$ concentrations in both phases. 


\section{Time-resolved laser-induced fluorescence spectroscopy}

Sample solutions containing $1.0 \times 10^{-4} \mathrm{~mol} \mathrm{dm}^{-3} \mathrm{Eu}(\mathrm{III})$ chelate were prepared by dissolving an appropriate amount of solid $\left[\mathrm{Eu}(\mathrm{tta})_{3}\left(\mathrm{H}_{2} \mathrm{O}\right)_{3}\right]$ in $\left[\mathrm{C}_{n} \mathrm{mim}\right]\left[\mathrm{Tf}_{2} \mathrm{~N}\right](n=2,4,6,8$, and 10), $\left[\mathrm{C}_{4} \mathrm{dmim}\right]\left[\mathrm{Tf}_{2} \mathrm{~N}\right]$, or organic solvents such as diisopropyl ether (DIPE), isobutyl methyl ketone (MIBK), benzene, and 1,2dichloroethane (DCE), which were pre-saturated with $\mathrm{H}_{2} \mathrm{O}$ or $\mathrm{D}_{2} \mathrm{O}$. To prepare the solution of $\left[\mathrm{Eu}(\mathrm{tta})_{3}\left(\mathrm{D}_{2} \mathrm{O}\right)_{3}\right]$, a small amount of $\left[\mathrm{Eu}(\mathrm{tta})_{3}\left(\mathrm{H}_{2} \mathrm{O}\right)_{3}\right]$ was dissolved in $\mathrm{D}_{2} \mathrm{O}$-saturated solvents, which contain large excess of $\mathrm{D}_{2} \mathrm{O}$ over $\mathrm{H}_{2} \mathrm{O}$ arising from solid $\left[\mathrm{Eu}(\mathrm{tta})_{3}\left(\mathrm{H}_{2} \mathrm{O}\right)_{3}\right]$. The sample solutions of $\left[\mathrm{Eu}(\mathrm{tta})_{3}\left(\mathrm{D}_{2} \mathrm{O}\right)_{3}\right]$ were covered with $\mathrm{D}_{2} \mathrm{O}$ until just before measurement in order to prevent isotope exchange with atmospheric water. Mixed solvents were prepared as given below, and used to examine the effect of the water and $\mathrm{Tf}_{2} \mathrm{~N}^{-}$concentrations in ILs on the hydration number of $\mathrm{Eu}(\mathrm{tta})_{3}$. The water concentration in $\left[\mathrm{C}_{2} \mathrm{mim}\right]\left[\mathrm{Tf}_{2} \mathrm{~N}, \mathrm{ClO}_{4}\right]$ and $\left[\mathrm{C}_{2} \mathrm{mim}\right]\left[\mathrm{ClO}_{4}\right]$ was adjusted to be 5.0 $(9.0 \mathrm{vol} \%)$ or 20 (36 vol\%) $\mathrm{mol} \mathrm{dm}^{-3}$ by adding water, while the $\mathrm{Tf}_{2} \mathrm{~N}^{-}$concentration in $\left[\mathrm{C}_{2} \mathrm{mim}\right]\left[\mathrm{Tf}_{2} \mathrm{~N}, \mathrm{ClO}_{4}\right]$ was kept constant at $0.50 \mathrm{~mol} \mathrm{dm}{ }^{-3}$ (13 vol\%). On the other hand, the $\mathrm{Tf}_{2} \mathrm{~N}^{-}$ concentration in sample solutions was made to vary from 0 to $1.7(50 \mathrm{vol} \%) \mathrm{mol} \mathrm{dm}^{-3}$ by dilution of $\left[\mathrm{C}_{4} \mathrm{mim}\right]\left[\mathrm{Tf}_{2} \mathrm{~N}\right]$ with DCE.

The fluorescence spectrum and lifetime of the $\mathrm{Eu}(\mathrm{III})$ chelate in $\left[\mathrm{C}_{n} \mathrm{mim}\right]\left[\mathrm{Tf}_{2} \mathrm{~N}\right]$, the organic solvents, and the mixed solvents were measured using a pulse-laser detection system. The excitation pulse used in this study was obtained from the fourth harmonic of a Nd:YAG laser (Quantel) coupled with an optical parametric oscillator unit (Opotek Inc.) and the second harmonic of a Ti:sapphire laser (Tsunami, Spectra-Physics) coupled with a regenerative amplifier (Spitfire, SpectraPhysics) and a frequency doubler/pulse selector (model 3890, Spectra-Physics) to increase the output energy and to convert the wavelength of the laser light to $394 \mathrm{~nm}$. For the measurements by the Nd:YAG laser, the pulse width was about $5 \mathrm{~ns}$ and the laser power at the sample location was generally 1-3 mJ per pulse at a repetition rate of $10 \mathrm{~Hz}$. For the measurements by the Ti:sapphire laser, the pulse width, the laser power at the sample location, and the repetition rate were $130 \mathrm{fs}, 0.1-0.5 \mathrm{~mJ}$ per pulse, and $100 \mathrm{~Hz}$, respectively. The fluorescence spectrum was measured by a time-gated ICCD camera (iStar, Andor Technology), and multiple measurements were performed. The gate width and step were both $100 \mu$ s and the initial delay was 10 or $10.5 \mu$ s. The fluorescence emission of the ${ }^{5} \mathrm{D}_{0} \rightarrow{ }^{7} \mathrm{~F}_{2}$ transition at $613 \mathrm{~nm}$ was processed using a least-squares fitting to obtain the fluorescence lifetime and the decay constant of the Eu(III) chelate.

\section{Electrospray ionization mass spectrometry}

The sample solution was prepared by dissolving $3.0 \times 10^{-2} \mathrm{~mol}$ $\mathrm{dm}^{-3}\left[\mathrm{Eu}(\mathrm{tta})_{3}\left(\mathrm{H}_{2} \mathrm{O}\right)_{3}\right]$ in water-saturated DCE containing 1.0 vol\% $\left[\mathrm{C}_{4} \mathrm{mim}\right]\left[\mathrm{Tf}_{2} \mathrm{~N}\right]$. The mass spectrum of $\left[\mathrm{Eu}(\mathrm{tta})_{3}\left(\mathrm{H}_{2} \mathrm{O}\right)_{3}\right]$ in the $\left[\mathrm{C}_{4} \mathrm{mim}\right]\left[\mathrm{Tf}_{2} \mathrm{~N}\right]$-DCE-mixed solvent was measured by ESI-MS (JEOL JMS-T100TD) immediately after sample dilution (100fold) with pure DCE. The measurements were carried out in negative ion mode, and operating parameters were as follows: needle voltage, $-2350 \mathrm{~V}$; ring lens voltage, $-10 \mathrm{~V}$; orifice 1 voltage, $-30 \mathrm{~V}$; orifice 2 voltage, $-5 \mathrm{~V}$; desolvation temperature, $250{ }^{\circ} \mathrm{C}$; orifice 1 temperature, $80{ }^{\circ} \mathrm{C}$.

\section{Results and discussion}

\section{Distribution equilibrium of Eu(III) chelates between IL and water}

The distribution ratio of Eu(III) with $5.0 \times 10^{-3} \mathrm{~mol} \mathrm{dm}^{-3} \mathrm{Htta}$ in $\left[\mathrm{C}_{n} \mathrm{mim}\right]\left[\mathrm{Tf}_{2} \mathrm{~N}\right]$ was investigated as a function of $\mathrm{pH}$ in the aqueous phase. The average recovery of $\mathrm{Eu}(\mathrm{III})$ after the extraction in $\left[\mathrm{C}_{6} \mathrm{mim}\right]\left[\mathrm{Tf}_{2} \mathrm{~N}\right]$ and $\left[\mathrm{C}_{8} \mathrm{mim}\right]\left[\mathrm{Tf}_{2} \mathrm{~N}\right]$ was $95 \%$. The $D$ values in the $\mathrm{pH}$ region of 3-5 decreased in the following order: $\left[\mathrm{C}_{8} \mathrm{mim}\right]\left[\mathrm{Tf}_{2} \mathrm{~N}\right] \approx\left[\mathrm{C}_{6} \mathrm{mim}\right]\left[\mathrm{Tf}_{2} \mathrm{~N}\right] \gg\left[\mathrm{C}_{4} \mathrm{mim}\right]\left[\mathrm{Tf}_{2} \mathrm{~N}\right]$. This suggests that the hydrophobic property of the ILs or the mutual solubility with water is an important factor in the distribution of Eu(III) chelates. Since the slopes of $\log D$ vs. $\mathrm{pH}$ plots ranged from 3 to 4 in each IL, it is found that 3-4 protons take part in the distribution equilibrium of Eu(III) chelates.

Hence, given that $\mathrm{Eu}(\mathrm{III})$ is extracted with $\mathrm{Htta}$ in $\left[\mathrm{C}_{n} \mathrm{mim}\right]$ $\left[\mathrm{Tf}_{2} \mathrm{~N}\right]$ as a mixture of neutral $\mathrm{Eu}(\mathrm{tta})_{3}$ and anionic $\mathrm{Eu}(\mathrm{tta})_{4}{ }^{-}$ chelates as reported previously, ${ }^{23,28}$ the distribution ratio of $\mathrm{Eu}(\mathrm{III})$ can be expressed as follows:

$$
D=\frac{\left[\mathrm{Eu}(\mathrm{tta})_{3}\right]_{\mathrm{IL}}+\left[\mathrm{Eu}(\mathrm{tta})_{4}^{-}\right]_{\mathrm{IL}}}{\left[\mathrm{Eu}^{3+}\right]},
$$

where the subscript IL denotes the IL phase. The distribution equilibria and the extraction constants of the neutral $\left(K_{\mathrm{ex}, 3}\right)$ and anionic $\left(K_{\mathrm{ex}, 4}\right)$ chelates can be written as:

$$
\begin{gathered}
\mathrm{Eu}^{3+}+3 \mathrm{Htta}_{\mathrm{IL}} \rightleftharpoons \mathrm{Eu}(\mathrm{tta})_{3, \mathrm{IL}}+3 \mathrm{H}^{+}, \\
K_{\mathrm{ex}, 3}=\frac{\left[\mathrm{Eu}(\mathrm{tta})_{3}\right]_{\mathrm{IL}}\left[\mathrm{H}^{+}\right]^{3}}{\left[\mathrm{Eu}^{3+}\right][\mathrm{Htta}]_{\mathrm{IL}}{ }^{3}},
\end{gathered}
$$

and

$$
\begin{gathered}
\mathrm{Eu}^{3+}+4 \mathrm{Htta}_{\mathrm{IL}}+\mathrm{Tf}_{2} \mathrm{~N}^{-}{ }_{\mathrm{IL}} \rightleftharpoons \mathrm{Eu}(\mathrm{tta})_{4}{ }^{-}{ }_{\mathrm{IL}}+4 \mathrm{H}^{+}+\mathrm{Tf}_{2} \mathrm{~N}^{-}, \\
K_{\mathrm{ex}, 4}=\frac{\left[\mathrm{Eu}(\mathrm{tta})_{4}{ }^{-}\right]_{\mathrm{IL}}\left[\mathrm{H}^{+}\right]^{4}\left[\mathrm{Tf}_{2} \mathrm{~N}^{-}\right]}{\left[\mathrm{Eu}^{3+}\right][\mathrm{Htta}]_{\mathrm{IL}}{ }^{4}\left[\mathrm{Tf}_{2} \mathrm{~N}^{-}\right]_{\mathrm{IL}}}
\end{gathered}
$$

respectively. Given that $\left[\mathrm{Tf}_{2} \mathrm{~N}^{-}\right]$and $\left[\mathrm{Tf}_{2} \mathrm{~N}^{-}\right]_{\mathrm{IL}}$ for the respective ILs are constant under the stated conditions, eqn (6) may be rewritten as follows:

$$
K_{\mathrm{ex}, 4}^{\prime}=\frac{K_{\mathrm{ex}, 4}\left[\mathrm{Tf}_{2} \mathrm{~N}^{-}\right]_{\mathrm{IL}}}{\left[\mathrm{Tf}_{2} \mathrm{~N}^{-}\right]}=\frac{\left[\mathrm{Eu}(\mathrm{tta})_{4}{ }^{-}\right]_{\mathrm{IL}}\left[\mathrm{H}^{+}\right]^{4}}{\left[\mathrm{Eu}^{3+}\right][\mathrm{Htta}]_{\mathrm{IL}}{ }^{4}}
$$

From eqn (2), (4) and (7), the following equation can be derived:

$$
D=\frac{\left[\mathrm{tta}^{-}\right]^{3} K_{\mathrm{D}, \mathrm{HA}}{ }^{3} K_{\mathrm{ex}, 3}}{K_{\mathrm{a}}{ }^{3}}+\frac{\left[\mathrm{tta}^{-}\right]^{4} K_{\mathrm{D}, \mathrm{HA}}{ }^{4} K_{\mathrm{ex}, 4}^{\prime}}{K_{\mathrm{a}}{ }^{4}},
$$

where $\left[\mathrm{tta}^{-}\right], K_{\mathrm{D}, \mathrm{HA}}$, and $K_{\mathrm{a}}$ are the concentration of $\mathrm{tta}^{-}$dissociated in the aqueous phase, the distribution constant of Htta, and the acid-dissociation constant of Htta, respectively. The constants used in this study were $K_{\mathrm{a}}=10^{-6.33}$ (ref. 45 ) and $K_{\mathrm{D}, \mathrm{HA}}$ $=10^{1.61}, 10^{1.68}$, and $10^{1.64}$ for $\left[\mathrm{C}_{4} \mathrm{mim}\right]\left[\mathrm{Tf}_{2} \mathrm{~N}\right],\left[\mathrm{C}_{6} \mathrm{mim}\right]\left[\mathrm{Tf}_{2} \mathrm{~N}\right]$, 
and $\left[\mathrm{C}_{8} \mathrm{mim}\right]\left[\mathrm{Tf} \mathrm{f}_{2} \mathrm{~N}\right],{ }^{27}$ respectively. The value for the $\mathrm{tta}^{-}$ concentration in the aqueous phase can be calculated as follows:

$$
\left[\mathrm{tta}^{-}\right]=\frac{[\mathrm{Htta}]_{\mathrm{ini}} K_{\mathrm{a}}}{\left(K_{\mathrm{D}, \mathrm{HA}}+1\right)\left[\mathrm{H}^{+}\right]+\left(K_{\mathrm{D}, \mathrm{A}}+1\right) K_{\mathrm{a}}},
$$

where $[\mathrm{Htta}]_{\text {ini }}$ and $K_{\mathrm{D}, \mathrm{A}}$ are the initial concentration of $\mathrm{Htta}$ in $\left[\mathrm{C}_{n} \operatorname{mim}\right]\left[\mathrm{Tf}_{2} \mathrm{~N}\right]$ and the apparent distribution constant of $\mathrm{tta}^{-}$, respectively. The $K_{\mathrm{D}, \mathrm{A}}$ values used were $10^{0.96}, 10^{1.18}$, and $10^{1.40}$ for $\left[\mathrm{C}_{4} \mathrm{mim}\right]\left[\mathrm{Tf}_{2} \mathrm{~N}\right], \quad\left[\mathrm{C}_{6} \mathrm{mim}\right]\left[\mathrm{Tf}_{2} \mathrm{~N}\right]$, and $\left[\mathrm{C}_{8} \mathrm{mim}\right]\left[\mathrm{Tf}_{2} \mathrm{~N}\right],{ }^{27}$ respectively.

To determine the extraction constants of the $\mathrm{Eu}(\mathrm{III})$ chelates, the distribution equilibria in the $\left[\mathrm{C}_{n} \operatorname{mim}\right]\left[\mathrm{Tf}_{2} \mathrm{~N}\right]$ systems were examined in detail. Fig. 2 shows the distribution ratio of $\mathrm{Eu}(\mathrm{III})$ as a function of the $\mathrm{tta}^{-}$concentration in the aqueous phase ( $\mathrm{pH}$ 2.5-5.4) at the different concentrations of $\mathrm{Htta}$ in [ $\left.\mathrm{C}_{n} \mathrm{mim}\right]$ $\left[\mathrm{Tf}_{2} \mathrm{~N}\right]$. The slopes of the plots increased from 3 to 4 at the lower and higher $\mathrm{tta}^{-}$concentration, respectively. Therefore, in the $\left[\mathrm{C}_{n} \operatorname{mim}\right]\left[\mathrm{Tf}_{2} \mathrm{~N}\right]$ systems, Eu(III) was extracted into $\left[\mathrm{C}_{n} \operatorname{mim}\right]\left[\mathrm{Tf}_{2} \mathrm{~N}\right]$ as the neutral $\mathrm{Eu}(\mathrm{tta})_{3}$ and the anionic $\mathrm{Eu}(\mathrm{tta})_{4}{ }^{-}$chelates. The values of $K_{\mathrm{ex}, 3}$ and $K_{\mathrm{ex}, 4}^{\prime}$ in the $\left[\mathrm{C}_{n} \operatorname{mim}\right]\left[\mathrm{Tf}_{2} \mathrm{~N}\right]$ systems were determined by a non-linear least-squares fitting of the plots, and the results are shown in Table 1 . The $K_{\mathrm{ex}, 3}$ values in the organic solvent systems were calculated from the distribution data in the respective references for DIPE, ${ }^{46} \mathrm{MIBK},{ }^{47,48}$ benzene, ${ }^{46}$ and DCE. ${ }^{49}$ Additionally, the two-phase stability constant, $K_{\mathrm{D}, \mathrm{M}} \beta_{3}$, can be calculated from the $K_{\mathrm{ex}, 3}$ value as follows:

$$
K_{\mathrm{D}, \mathrm{M}} \beta_{3}=\frac{K_{\mathrm{ex}, 3} K_{\mathrm{D}, \mathrm{HA}}{ }^{3}}{K_{\mathrm{a}}{ }^{3}}
$$

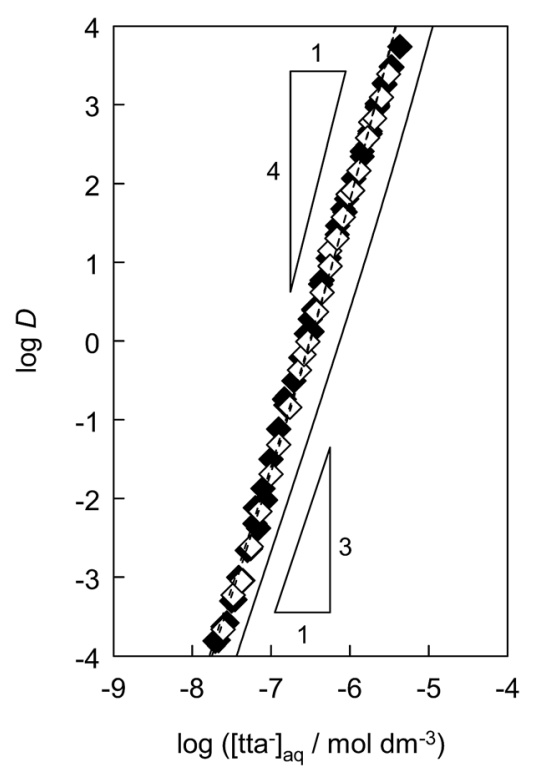

Fig. 2 Distribution ratio of Eu(III) as a function of $\mathrm{tta}^{-}$concentration in the aqueous phase in the $\left[\mathrm{C}_{4}\right.$ mim] $\left[\mathrm{Tf}_{2} \mathrm{~N}\right]^{28}$ (solid line), $\left[\mathrm{C}_{6}\right.$ mim] $\left[\mathrm{Tf}_{2} \mathrm{~N}\right]$ $(\diamond)$, and $\left[\mathrm{C}_{8} \mathrm{mim}\right]\left[\mathrm{Tf}_{2} \mathrm{~N}\right](\diamond)$ systems. The triangles express the respective slopes. Initial concentration of $\mathrm{Htta}$ was $1.0 \times 10^{-3}$ to $1.6 \times$ $10^{-2} \mathrm{~mol} \mathrm{dm}^{-3}$. Aqueous phase $\mathrm{pH}$ was $2.5-5.4$. The dashed lines were obtained by a non-linear least-squares fitting. where $K_{\mathrm{D}, \mathrm{M}}$ and $\beta_{3}$ represent the distribution constant of the neutral $\mathrm{Eu}(\mathrm{tta})_{3}$ chelate and the overall formation constant of a $1: 3$ chelate in the aqueous phase, respectively. The calculated $K_{\mathrm{D}, \mathrm{M}} \beta_{3}$ values are shown in Table 1 . The values of both $K_{\mathrm{ex}, 3}$ and $K^{\prime}{ }_{\text {ex, }}$ in the $\left[\mathrm{C}_{n} \mathrm{mim}\right]\left[\mathrm{Tf}_{2} \mathrm{~N}\right]$ systems increase with an increase in IL cation 1-alkyl chain length. This result indicated that the enhanced $D$ values for $\mathrm{Eu}(\mathrm{III})$ in $\left[\mathrm{C}_{6} \mathrm{mim}\right]\left[\mathrm{Tf}_{2} \mathrm{~N}\right]$ and $\left[\mathrm{C}_{8} \mathrm{mim}\right]$ $\left[\mathrm{Tf}_{2} \mathrm{~N}\right]$ are caused by an increase in the extraction constants of both the neutral and the anionic $\mathrm{Eu}(\mathrm{III})$ chelates. The $K_{\mathrm{ex}, 3}$ values in the $\left[\mathrm{C}_{n} \operatorname{mim}\right]\left[\mathrm{Tf}_{2} \mathrm{~N}\right]$ systems are higher than those in the DIPE, MIBK, benzene, and DCE systems. This finding is ascribed to the large values of $K_{\mathrm{D}, \mathrm{M}} K_{\mathrm{D}, \mathrm{HA}}{ }^{-3}$ in the $\left[\mathrm{C}_{n} \operatorname{mim}\right]\left[\mathrm{Tf}_{2} \mathrm{~N}\right]$ system because $K_{\mathrm{ex}, 3}$ is described by $K_{\mathrm{D}, \mathrm{M}} \beta_{3} K_{\mathrm{a}}{ }^{3} K_{\mathrm{D}, \mathrm{HA}}{ }^{-3}$ as shown in eqn (10). In a series of $\left[\mathrm{C}_{n} \mathrm{mim}\right]\left[\mathrm{Tf}_{2} \mathrm{~N}\right]$, because the $K_{\mathrm{D}, \mathrm{HA}}$ values are almost independent of the 1-alkyl chain length of the IL cation, the $K_{\mathrm{ex}, 3}$ values depend solely on $K_{\mathrm{D}, \mathrm{M}}$. Thus, the higher values of $K_{\mathrm{ex}, 3}$ in $\left[\mathrm{C}_{6} \mathrm{mim}\right]\left[\mathrm{Tf}_{2} \mathrm{~N}\right]$ and $\left[\mathrm{C}_{8} \mathrm{mim}\right]\left[\mathrm{Tf}_{2} \mathrm{~N}\right]$ were attributed to the respective $K_{\mathrm{D}, \mathrm{M}}$ values. In contrast, the $K_{\mathrm{ex}, 4}^{\prime}$ values were affected by the solubility products $\left(K_{\mathrm{sp}}=\left[\mathrm{C}_{n} \mathrm{mim}^{+}\right] \times\left[\mathrm{Tf}_{2} \mathrm{~N}^{-}\right]\right)$of the ILs because $K_{\mathrm{ex}, 4}^{\prime}$ is derived from the anion-exchange extraction constant shown in eqn (6). The $K_{\text {sp }}$ value of $\left[\mathrm{C}_{n} \operatorname{mim}\right]\left[\mathrm{Tf}_{2} \mathrm{~N}\right]$ decreased with an increase in the 1-alkyl chain length of the IL cation, i.e., $2.9 \times 10^{-4}>2.8 \times 10^{-5}>3.5 \times 10^{-6}$ $\mathrm{mol}^{2} \mathrm{dm}^{-6}$ for $\left[\mathrm{C}_{4} \mathrm{mim}\right]\left[\mathrm{Tf}_{2} \mathrm{~N}\right],\left[\mathrm{C}_{6} \mathrm{mim}\right]\left[\mathrm{Tf}_{2} \mathrm{~N}\right]$, and $\left[\mathrm{C}_{8} \mathrm{mim}\right]$ $\left[\mathrm{Tf}_{2} \mathrm{~N}\right],^{50}$ respectively. The distribution of the anionic $\mathrm{Eu}(\mathrm{tta})_{4}{ }^{-}$ chelate, $K_{\text {ex }, 4}^{\prime}$, increased with a decrease in $\mathrm{Tf}_{2} \mathrm{~N}^{-}$concentration in the aqueous phase in accord with the equilibrium shift (Le Chatelier's principle).

\section{Evaluation of the $K_{\mathrm{D}, \mathrm{M}}$ value based on the regular solution theory}

The values of $K_{\mathrm{D}, \mathrm{M}} \beta_{3}$ obtained for $\left[\mathrm{C}_{n} \operatorname{mim}\right]\left[\mathrm{Tf}_{2} \mathrm{~N}\right]$ were close to those obtained for oxygen-containing organic solvents such as MIBK and DIPE (Table 1). Because $\beta_{3}$ is independent of the extraction solvents, the effect of ILs on $K_{\mathrm{ex}, 3}$ can be discussed using $K_{\mathrm{D}, \mathrm{M}} \beta_{3}$. Hence, the order of $K_{\mathrm{D}, \mathrm{M}}$ values becomes as follows: MIBK $>\left[\mathrm{C}_{6} \operatorname{mim}\right]\left[\mathrm{Tf}_{2} \mathrm{~N}\right] \approx\left[\mathrm{C}_{8} \mathrm{mim}\right]\left[\mathrm{Tf}_{2} \mathrm{~N}\right]>\left[\mathrm{C}_{4} \mathrm{mim}\right]$ $\left[\mathrm{Tf}_{2} \mathrm{~N}\right]>$ DIPE $>$ benzene $\approx$ DCE.

Given that $\beta$-diketones exist in solution, including IL solutions, as a mixture of the keto and enol forms, the distribution constant of the enol form $\left(K_{\mathrm{D}, \mathrm{HE}}\right)$ as a proton complex in various solvents was calculated ${ }^{27,46,48,49}$ and used for the discussion. The distribution constant of a solute, expressed on the mole fraction scale $\left(K_{\mathrm{D}}^{\circ}\right)$, can be written using a modified equation based on the regular solution theory: $:^{51,52}$

$$
\ln K_{\mathrm{D}}^{\circ}=\frac{V_{2}}{R T}\left\{C_{\mathrm{ww}}-C_{\mathrm{oo}}+2\left(C_{\mathrm{o} 2}-C_{\mathrm{w} 2}\right)\right\},
$$

where $V$ and $C$ are the molar volume and the cohesive energy density, respectively. The subscripts $2, \mathrm{w}$, and o denote the solute, water, and organic solvent, respectively, and the terms $C_{\mathrm{o} 2}$ and $C_{\mathrm{w} 2}$ stand for the cohesive energy density between the solvent and solute molecules. If the interactions between the neutral solute and organic solvent molecules are caused mainly by their dispersion forces, the geometric mean approximation for the solubility parameter $(\delta)$ is applicable, i.e., $C_{\mathrm{o} 2} \approx \delta_{\mathrm{o}} \delta_{2}$. Hence, eqn (11) can be rewritten as: 
Table 1 Extraction constants of Eu(tta) ${ }_{3}$ and Eu(tta) ${ }_{4}^{-}$, distribution constants of the enol form of 2-thenoyltrifluoroacetone (Htta), and the twophase stability constants of $\mathrm{Eu}(\mathrm{tta})_{3}$ in the $\mathrm{Eu}(\mathrm{III})-\mathrm{Htta}-\left[\mathrm{C}_{n} \mathrm{mim}\right]\left[\mathrm{Tf} \mathrm{f}_{2} \mathrm{~N}\right]$ and -organic solvent systems at $25^{\circ} \mathrm{C}$

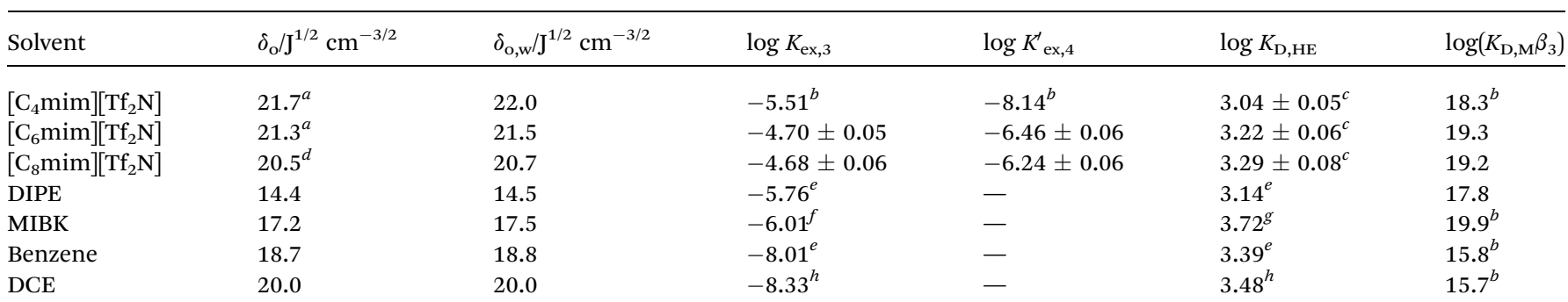

${ }^{a}$ Calculated from standard molar enthalpy of vaporization ${ }^{53}$ and density. ${ }^{44}{ }^{b}$ Ref. $28 .{ }^{c}$ Ref. $27 .{ }^{d}$ Calculated from standard molar enthalpy of vaporization ${ }^{53}$ and density. ${ }^{55}$ Calculated from ref. $46 .{ }^{f}$ Calculated from ref. 47 and $48 .{ }^{g}$ Calculated from ref. $48 .{ }^{h}$ Calculated from ref. 49.

$$
\frac{R T}{V_{2}} \ln K_{\mathrm{D}}^{\circ}+\delta_{\mathrm{o}}^{2}=2 \delta_{2} \delta_{\mathrm{o}}+C_{\mathrm{ww}}-2 C_{\mathrm{w} 2}
$$

The solubility parameter of a water-saturated organic solvent $\left(\delta_{\mathrm{o}, \mathrm{w}}\right)$ was calculated using the conventional solubility parameter for the aqueous solution $\left(\delta_{\mathrm{w}}=35.8 \mathrm{~J}^{1 / 2} \mathrm{~cm}^{-3 / 2}\right)$ as follows:

$$
\delta_{\mathrm{o}, \mathrm{w}}=\phi_{\mathrm{o}} \delta_{\mathrm{o}}+\phi_{\mathrm{w}} \delta_{\mathrm{w}}
$$

where $\phi$ is the volume fraction. Plots of the left-hand side of eqn (12) using $\delta_{\mathrm{o}, \mathrm{w}}$ instead of $\delta_{\mathrm{o}}$ versus $\delta_{\mathrm{o}, \mathrm{w}}$ are expected to be a straight line. The apparent solubility parameter of the solute $\left(\delta_{2}\right)$ can be obtained from the slope. The solubility parameters of $\left[\mathrm{C}_{n} \mathrm{mim}\right]\left[\mathrm{Tf}_{2} \mathrm{~N}\right]\left(\delta_{\mathrm{IL}}\right)$ were calculated from the standard molar enthalpies of vaporization ${ }^{53}$ and the densities, ${ }^{54,55}$ and are listed in Table 1. The values of $\left(K_{\mathrm{D}}^{\circ}\right)$ for the enol form of $\mathrm{Htta}\left(K_{\mathrm{D}, \mathrm{HE}}^{\circ}\right)$ and $\mathrm{Eu}(\mathrm{tta})_{3}\left(K_{\mathrm{D}, \mathrm{M}}^{\circ}\right)$ were calculated, and the molar volume of $\mathrm{Htta}, 160 \mathrm{~cm}^{3} \mathrm{~mol}^{-1}$, was taken from the literature. ${ }^{56}$ The molar volume of the $\mathrm{Eu}(\mathrm{tta})_{3}$ chelate was estimated to be $448 \mathrm{~cm}^{3}$ $\mathrm{mol}^{-1}$ from an empirical relation between that of Htta and $\mathrm{Hf}(\mathrm{tta})_{4} \cdot{ }^{57,58}$

Fig. 3 shows the plots based on eqn (12) for the neutral $\mathrm{Eu}(\mathrm{tta})_{3}$ chelate in $\left[\mathrm{C}_{n} \mathrm{mim}\right]\left[\mathrm{Tf}_{2} \mathrm{~N}\right]$ and various organic solvents including benzene, DCE, DIPE, and MIBK ${ }^{46-49,59}$ along with the enol form of Htta as a proton complex. Because of the lack of a reliable value of $\beta_{3}$ for $\mathrm{Eu}(\mathrm{tta})_{3}$, the $K_{\mathrm{D}, \mathrm{M}}^{\circ} \beta_{3}$ value was used instead of $K_{\mathrm{D}, \mathrm{M}}^{\circ}$ for the subsequent discussion. A linear relationship was observed for the enol of $\mathrm{Htta}$ in all of the organic solvents including $\left[\mathrm{C}_{n} \operatorname{mim}\right]\left[\mathrm{Tf}_{2} \mathrm{~N}\right]$. This result indicated that the $\left[\mathrm{C}_{n} \operatorname{mim}\right]\left[\mathrm{Tf}_{2} \mathrm{~N}\right]$ solutions of the enol of $\mathrm{Htta}$ behave like a regular solution as observed in conventional organic solutions. The same is true for the evaluation of the distribution constant of the enol form of Htta expressed on the molar concentration scale. ${ }^{27}$ Consequently, the value of $\delta_{2}$ for the enol form of Htta was obtained as $18.6 \pm 0.5 \mathrm{~J}^{1 / 2} \mathrm{~cm}^{-3 / 2}$ from the slope of the straight line.

In contrast to the enol of $\mathrm{Htta}$, the plots for the neutral $\mathrm{Eu}(\mathrm{tta})_{3}$ chelate in $\left[\mathrm{C}_{n} \mathrm{mim}\right]\left[\mathrm{Tf}_{2} \mathrm{~N}\right]$ and in oxygen-containing organic solvents such as ketones, ethers, and esters show a large positive deviation from the straight line obtained for alkanes, aromatic hydrocarbons, and chlorohydrocarbons, which are nonpolar or inert solvents. This deviation clearly demonstrates the existence of specific solute-solvent interactions between $\mathrm{Eu}(\mathrm{tta})_{3}$ and $\left[\mathrm{C}_{n} \mathrm{mim}\right]\left[\mathrm{Tf}_{2} \mathrm{~N}\right]$, i.e., inner- and/or outer-sphere solvation effects ( $c f$. Fig. S1†). Since such specific interactions with $\mathrm{Eu}(\mathrm{tta})_{3}$ cannot be generated by the inert solvent molecules, it is expected that the slope of the straight line for $\mathrm{Eu}(\mathrm{tta})_{3}$ gives its $\delta_{2}$ value in those inert solvents. The value obtained, $21.1 \pm 0.6 \mathrm{~J}^{1 / 2} \mathrm{~cm}^{-3 / 2}$, which is much larger than that of the enol, reflects the hydrated states of $\mathrm{Eu}(\mathrm{tta})_{3}$ in those solvents as will be discussed later by TRLFS. On the other hand, the values of $\delta_{2}$ for $\mathrm{Eu}(\mathrm{tta})_{3}$ calculated from the linear

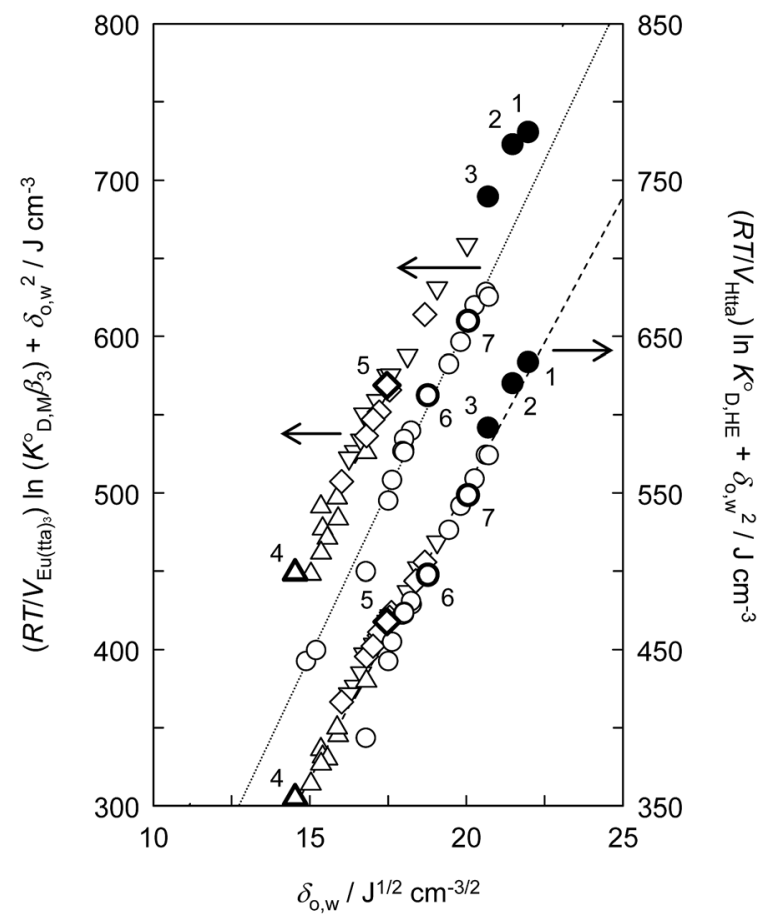

Fig. 3 Evaluation of the effect on the distribution constant of the neutral $\mathrm{Eu}(\mathrm{tta})_{3}$ chelate and the distribution constant of the enol form of $\mathrm{Htta}$ on the basis of the regular solution theory. (O), $\left[\mathrm{C}_{n} \operatorname{mim}\right]\left[\mathrm{Tf}_{2} \mathrm{~N}\right]$; $(\bigcirc)$, alkanes, aromatic hydrocarbons, and chlorohydrocarbons; ${ }^{46,49}$ $(\diamond)$, ketones; ${ }^{47,48}(\triangle)$, ethers; ${ }^{46}(\nabla)$, esters. ${ }^{47,59}(1),\left[\mathrm{C}_{4} \mathrm{mim}\right]\left[\mathrm{Tf}_{2} \mathrm{~N}\right] ;(2)$, $\left[\mathrm{C}_{6} \mathrm{mim}\right]\left[T f_{2} \mathrm{~N}\right]$; (3), [ $\left.\mathrm{C}_{8} \mathrm{mim}\right]\left[\mathrm{Tf}_{2} \mathrm{~N}\right]$; (4), DIPE; (5), MIBK; (6), benzene; (7), $\mathrm{DCE}$. The respective straight lines were obtained by a least-squares fitting of the Eu(tta) ${ }_{3}$ chelate for alkanes, aromatic hydrocarbons, and chlorohydrocarbons (dotted line) and for the enol form of $\mathrm{Htta}$ (dashed line). 
relationship for ketones, ethers, and esters were $20.3 \pm 0.6,17.8$ \pm 3.1 , and $18.2 \pm 0.7 \mathrm{~J}^{1 / 2} \mathrm{~cm}^{-3 / 2}$, respectively, which are significantly smaller than that in the inert solvents. Although the reliable $\delta_{2}$ value could not be obtained in $\left[\mathrm{C}_{n} \operatorname{mim}\right]\left[\mathrm{Tf}_{2} \mathrm{~N}\right]$ because of only 3 plots, the value was estimated to be about 17 $\mathrm{J}^{1 / 2} \mathrm{~cm}^{-3 / 2}$ and was relatively close to those in the oxygencontaining organic solvents. These results implied that the dehydration of the $\mathrm{Eu}(\mathrm{tta})_{3}$ chelate occurred in the oxygencontaining organic solvents and also $\left[\mathrm{C}_{n} \operatorname{mim}\right]\left[\mathrm{Tf}_{2} \mathrm{~N}\right]$.

\section{TRLFS of $\left[\mathrm{Eu}(\mathrm{tta})_{3}\left(\mathrm{H}_{2} \mathrm{O}\right)_{3}\right]$ in ILs}

To clarify such specific solvation effect in ILs, the hydration state in the first coordination sphere of the neutral $\mathrm{Eu}(\mathrm{III})$ chelate in $\left[\mathrm{C}_{n} \mathrm{mim}\right]\left[\mathrm{Tf}_{2} \mathrm{~N}\right]$ was examined by TRLFS. The fluorescence decay of $\left[\mathrm{Eu}(\mathrm{tta})_{3}\left(\mathrm{H}_{2} \mathrm{O}\right)_{3}\right]$ dissolved in a series of $\left[\mathrm{C}_{n} \operatorname{mim}\right]\left[\mathrm{Tf}_{2} \mathrm{~N}\right](n=2,4,6,8$, and 10$)$ and in $\left[\mathrm{C}_{4} \mathrm{dmim}\right]\left[\mathrm{Tf}_{2} \mathrm{~N}\right]$ saturated with $\mathrm{H}_{2} \mathrm{O}$ or $\mathrm{D}_{2} \mathrm{O}$ was measured by the excitation at $394 \mathrm{~nm}$, along with that in DIPE, MIBK, benzene, and DCE (the fluorescence spectra of $\left[\mathrm{Eu}(\mathrm{tta})_{3}\left(\mathrm{H}_{2} \mathrm{O}\right)_{3}\right]$ are shown in Fig. S2 and $\mathrm{S} 4 \uparrow$ and the fluorescence decay curves are shown in Fig. $\mathrm{S} 3$ and S5†). All decay curves were well fitted by a single exponential function as expected. Table 2 shows the mean fluorescence decay constants in those solvents saturated with $\mathrm{H}_{2} \mathrm{O}$ and $\mathrm{D}_{2} \mathrm{O}$ ( $k_{\mathrm{H}_{2} \mathrm{O}}$ and $k_{\mathrm{D}_{2} \mathrm{O}}$, respectively) and the mean $n_{\mathrm{H}_{2} \mathrm{O}}$ values, along with the estimated ${ }^{5} \mathrm{D}_{0}$ radiative decay constants $\left(k_{\mathrm{rad}}\right)$ obtained by summing over the radiative constants $k_{\text {rad, } 0 j}$ for each ${ }^{5} \mathrm{D}_{0} \rightarrow$ ${ }^{7} \mathrm{~F}_{j}$ transition as described in the ref. 60 and 61 . The $k_{\text {rad, } 0 j}$ values were calculated from the ratios of the integrated intensities of the ${ }^{5} \mathrm{D}_{0} \rightarrow{ }^{7} \mathrm{~F}_{j}$ transitions to that of the ${ }^{5} \mathrm{D}_{0} \rightarrow{ }^{7} \mathrm{~F}_{1}$ and the magnetic-dipole transition rate constant, $k_{\text {rad, } 01}=0.05 \mathrm{~ms}^{-1}{ }^{60}$ The $k_{\text {rad }}$ values were less affected by the solvents. In contrast, the $k_{\mathrm{D}_{2} \mathrm{O}}$ value varies depending on the solvents and is considerably higher than $k_{\text {rad }}$, which is consistent with the reported result in the $\mathrm{IL} .^{35}$ There is little change in the fluorescence intensity as well as the fluorescence lifetime and the hydration number of the $\mathrm{Eu}(\mathrm{tta})_{3}$ chelate in each IL for the three measurements. The uncertainty in the decay constants presented in Table 2 is the standard deviation between replicate experiments. Furthermore, the fluorescence lifetime and the

Table 2 Fluorescence decay constants, the number of coordinated water molecules, and radiative decay constants for $\left[\mathrm{Eu}(\mathrm{tta})_{3}\left(\mathrm{H}_{2} \mathrm{O}\right)_{3}\right]$ dissolved in $\left[\mathrm{C}_{n}\right.$ mim] $\left[\mathrm{Tf}_{2} \mathrm{~N}\right]$ and organic solvents saturated with $\mathrm{H}_{2} \mathrm{O}$ or $\mathrm{D}_{2} \mathrm{O}$

\begin{tabular}{lllll}
\hline Solvent & $k_{\mathrm{H}_{2} \mathrm{O}} / \mathrm{ms}^{-1}$ & $k_{\mathrm{D}_{2} \mathrm{O}} / \mathrm{ms}^{-1}$ & $n_{\mathrm{H}_{2} \mathrm{O}}$ & $k_{\mathrm{rad}} / \mathrm{ms}^{-1}$ \\
\hline$\left[\mathrm{C}_{2} \mathrm{mim}\right]\left[\mathrm{Tf}_{2} \mathrm{~N}\right]$ & $2.05 \pm 0.04$ & $2.06 \pm 0.04$ & 0 & $0.56 \pm 0.01$ \\
{$\left[\mathrm{C}_{4} \mathrm{mim}\right]\left[\mathrm{Tf}_{2} \mathrm{~N}\right]$} & $2.25^{a}$ & $2.02^{a}$ & $0.2^{a}$ & $0.75 \pm 0.01$ \\
{$\left[\mathrm{C}_{6} \mathrm{mim}\right]\left[\mathrm{Tf}_{2} \mathrm{~N}\right]$} & $1.89 \pm 0.01$ & $1.88 \pm 0.01$ & 0 & $0.68 \pm 0.01$ \\
{$\left[\mathrm{C}_{8} \mathrm{mim}\right]\left[\mathrm{Tf}_{2} \mathrm{~N}\right]$} & $1.88 \pm 0.02$ & $1.91 \pm 0.01$ & 0 & $0.60 \pm 0.01$ \\
{$\left[\mathrm{C}_{10} \mathrm{mim}\right]\left[\mathrm{Tf}_{2} \mathrm{~N}\right]$} & $1.87 \pm 0.04$ & $1.88 \pm 0.03$ & 0 & $0.60 \pm 0.01$ \\
{$\left[\mathrm{C}_{4} \mathrm{dmim}\right]\left[\mathrm{Tf}_{2} \mathrm{~N}\right]$} & $1.92 \pm 0.04$ & $1.92 \pm 0.02$ & 0 & $0.56 \pm 0.01$ \\
DIPE & $3.43 \pm 0.06$ & $2.48 \pm 0.05$ & 1.0 & $0.48 \pm 0.01$ \\
MIBK & $3.18 \pm 0.03$ & $1.97 \pm 0.02$ & 1.3 & $0.54 \pm 0.01$ \\
Benzene & $6.05^{a}$ & $3.75^{a}$ & $2.4^{a}$ & $0.60 \pm 0.02$ \\
DCE & $5.09^{a}$ & $3.76^{a}$ & $1.4^{a}$ & $0.62 \pm 0.01$
\end{tabular}

${ }^{a}$ Ref. 28 . hydration number were without dependence on the laser power from 0.005 to $1 \mathrm{~mJ}$ per pulse. These demonstrate that the decomposition of the $\mathrm{Eu}(\mathrm{tta})_{3}$ chelate and IL components by the laser irradiation was negligible under the present conditions.

The $\left[\mathrm{Eu}(\mathrm{tta})_{3}\left(\mathrm{H}_{2} \mathrm{O}\right)_{3}\right]$ complex was almost completely dehydrated in the series of $\left[\mathrm{C}_{n} \mathrm{mim}\right]\left[\mathrm{Tf}_{2} \mathrm{~N}\right]$ and $\left[\mathrm{C}_{4} \mathrm{dmim}\right]\left[\mathrm{Tf}_{2} \mathrm{~N}\right]$ saturated with water, whereas the hydrated complex was observed in DIPE, MIBK, benzene, and DCE. These results were in agreement with those obtained by TRLFS of the $\mathrm{Eu}(\mathrm{tta})_{3}$ chelate extracted with Htta into the same such solvents. ${ }^{28}$ In addition, the presence of $\mathrm{Cl}^{-}$had no effect on the dehydration of $\left[\mathrm{Eu}(\mathrm{tta})_{3}\left(\mathrm{H}_{2} \mathrm{O}\right)_{3}\right]$. Because the $n_{\mathrm{H}_{2} \mathrm{O}}$ values in $\left[\mathrm{C}_{n} \mathrm{mim}\right]\left[\mathrm{Tf}_{2} \mathrm{~N}\right]$ and $\left[\mathrm{C}_{4} \mathrm{dmim}\right]\left[\mathrm{Tf}_{2} \mathrm{~N}\right]$ were independent of the 1-alkyl chain length and the type of the IL cation, the cause of the dehydration observed in all of the ILs is ascribed to the common IL anion, $\mathrm{Tf}_{2} \mathrm{~N}^{-}$. Considering that the coordination number of $\mathrm{Eu}(\mathrm{III})$ is usually 8 or 9 in solution, it was, therefore, plausible that the $\mathrm{Tf}_{2} \mathrm{~N}^{-}$anions could coordinate to the neutral $\mathrm{Eu}(\mathrm{tta})_{3}$ chelate in $\left[\mathrm{C}_{n} \mathrm{mim}\right]\left[\mathrm{Tf}_{2} \mathrm{~N}\right]$ and replace the coordinated water molecules of $\left[\mathrm{Eu}(\mathrm{tta})_{3}\left(\mathrm{H}_{2} \mathrm{O}\right)_{3}\right]$. Although the donor number of $\left[\mathrm{C}_{n} \operatorname{mim}\right]\left[\mathrm{Tf}_{2} \mathrm{~N}\right], 7.5-11.2 \mathrm{kcal} \mathrm{mol}^{-1},{ }^{62}$ is significantly smaller than those of DIPE $\left(19.0 \mathrm{kcal} \mathrm{mol}^{-1}\right)$ and MIBK $(16.0 \mathrm{kcal}$ $\left.\mathrm{mol}^{-1}\right){ }_{,}^{63}$ it should be noted that the $\mathrm{p} K_{\mathrm{a}}$ value of the conjugate acid of $\mathrm{Tf}_{2} \mathrm{~N}^{-}, 1.7,{ }^{64}$ is much higher than those of DIPE $(-4.30)^{65}$ and MIBK. If the dehydrated adduct like $\left[\mathrm{Eu}(\mathrm{tta})_{3}\left(\mathrm{Tf}_{2} \mathrm{~N}\right)\right]^{-}$is formed in the IL, it may be more stable than the hydrated chelate like $\left[\mathrm{Eu}(\mathrm{tta})_{3}\left(\mathrm{H}_{2} \mathrm{O}\right)_{3}\right]$ in $\left[\mathrm{C}_{n} \mathrm{mim}\right]\left[\mathrm{Tf}_{2} \mathrm{~N}\right]$ because the adduct is more hydrophobic and is one of the IL component.

The effect of the water concentration in ILs on the solvation of $\mathrm{Eu}(\mathrm{tta})_{3}$ was investigated using the mixed solvent of $\left[\mathrm{C}_{2} \mathrm{mim}\right]$ $\left[\mathrm{Tf}_{2} \mathrm{~N}\right]$ with hydrophilic IL, $\left[\mathrm{C}_{2} \mathrm{mim}\right]\left[\mathrm{ClO}_{4}\right]$. Fig. 4 (a) shows the $n_{\mathrm{H}_{2} \mathrm{O}}$ value as a function of water concentration in $\left[\mathrm{C}_{2} \mathrm{mim}\right]$ $\left[\mathrm{Tf}_{2} \mathrm{~N}, \mathrm{ClO}_{4}\right]$ and $\left[\mathrm{C}_{2} \mathrm{mim}\right]\left[\mathrm{ClO}_{4}\right]$. The fluorescence spectra, the fluorescence decay curves, and the values of $k_{\mathrm{H}_{2} \mathrm{O}}, k_{\mathrm{D}_{2} \mathrm{O}} \mathrm{O}$, and $n_{\mathrm{H}_{2} \mathrm{O}}$ are shown in Fig. S6, S7 and Table S1, $\uparrow$ respectively. The Eu(tta) ${ }_{3}$ chelate exists as di- or tri-hydrates in $\left[\mathrm{C}_{2} \mathrm{mim}\right]\left[\mathrm{ClO}_{4}\right]$ containing $20 \mathrm{~mol} \mathrm{dm}^{-3}$ water, indicating that the $\mathrm{ClO}_{4}{ }^{-}$anion does not give rise to the dehydration of $\mathrm{Eu}(\mathrm{tta})_{3}$ in the IL. In contrast, mono-hydrated $\mathrm{Eu}(\mathrm{tta})_{3}$ chelate was formed in $\left[\mathrm{C}_{2} \mathrm{mim}\right]\left[\mathrm{Tf}_{2} \mathrm{~N}\right.$, $\mathrm{ClO}_{4}$ ] containing $0.50 \mathrm{~mol} \mathrm{dm}^{-3} \mathrm{Tf}_{2} \mathrm{~N}^{-}$and $20 \mathrm{~mol} \mathrm{dm}{ }^{-3}$ water. This means that the $\mathrm{Tf}_{2} \mathrm{~N}^{-}$anions displaced the coordinated water molecules of $\left[\mathrm{Eu}(\mathrm{tta})_{3}\left(\mathrm{H}_{2} \mathrm{O}\right)_{3}\right]$. The $n_{\mathrm{H}_{2} \mathrm{O}}$ value of $\mathrm{Eu}(\mathrm{tta})_{3}$ in the presence of $0.50 \mathrm{~mol} \mathrm{dm}{ }^{-3} \mathrm{Tf}_{2} \mathrm{~N}^{-}$decreased with a decrease in water concentration in $\left[\mathrm{C}_{2} \mathrm{mim}\right]\left[\mathrm{Tf}_{2} \mathrm{~N}, \mathrm{ClO}_{4}\right]$. Therefore, these observations prove the ligand displacement between water and $\mathrm{Tf}_{2} \mathrm{~N}^{-}$molecules in the $\mathrm{Eu}(\mathrm{tta})_{3}$ chelate in ILs.

To make sure of the coordination ability of $\mathrm{Tf}_{2} \mathrm{~N}^{-}$to $\mathrm{Eu}(\mathrm{tta})_{3}$, the effect of the $\mathrm{Tf}_{2} \mathrm{~N}^{-}$concentration in DCE containing varying amounts of $\left[\mathrm{C}_{4} \mathrm{mim}\right]\left[\mathrm{Tf}_{2} \mathrm{~N}\right]$ was investigated, and the results are shown in Fig. 4(b), S8, S9 and Table S2. $\dagger$ The partially-hydrated $\mathrm{Eu}(\mathrm{tta})_{3}$ chelate was found in DCE containing $0.10 \mathrm{vol} \%$ $\left[\mathrm{C}_{4} \mathrm{mim}\right]\left[\mathrm{Tf}_{2} \mathrm{~N}\right]\left(3.4 \times 10^{-3} \mathrm{~mol} \mathrm{dm}{ }^{-3} \mathrm{Tf}_{2} \mathrm{~N}^{-}\right)$saturated with water $\left(1.3 \times 10^{-1} \mathrm{~mol} \mathrm{dm}^{-3}\right)$. It is noteworthy that almost complete dehydration of $\left[\mathrm{Eu}(\mathrm{tta})_{3}\left(\mathrm{H}_{2} \mathrm{O}\right)_{3}\right]$ was observed even in 1.0 vol\% $\left[\mathrm{C}_{4} \mathrm{mim}\right]\left[\mathrm{Tf}_{2} \mathrm{~N}\right]$ solution $\left(3.4 \times 10^{-2} \mathrm{~mol} \mathrm{dm}^{-3} \mathrm{Tf}_{2} \mathrm{~N}^{-}\right)$ saturated with water $\left(1.3 \times 10^{-1} \mathrm{~mol} \mathrm{dm}^{-3}\right)$. Therefore, $\left[\mathrm{Eu}(\mathrm{tta})_{3}\left(\mathrm{H}_{2} \mathrm{O}\right)_{3}\right]$ was completely dehydrated in the mixed 

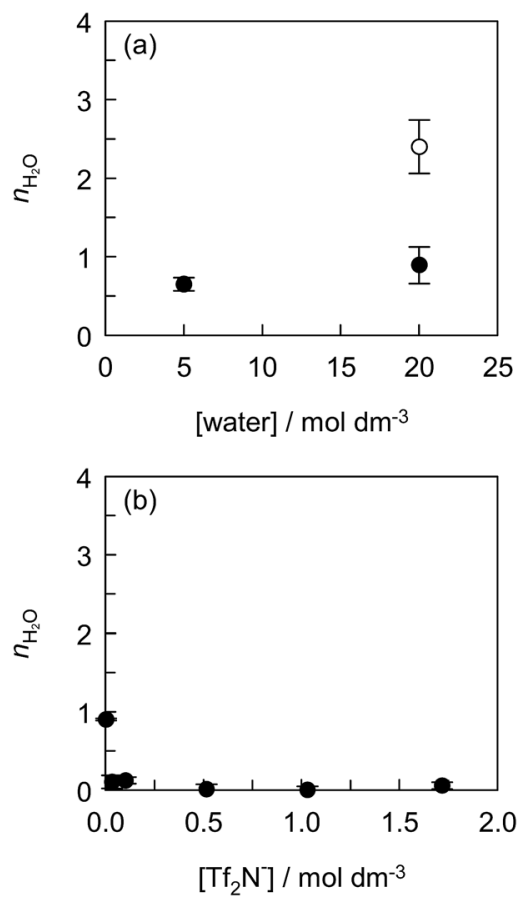

Fig. 4 Effect of water concentration in $\left[\mathrm{C}_{2} \mathrm{mim}\right]\left[\mathrm{Tf}_{2} \mathrm{~N}, \mathrm{ClO}_{4}\right](\mathbf{O})$ and $\left[\mathrm{C}_{2} \mathrm{mim}\right]\left[\mathrm{ClO}_{4}\right](\mathrm{O})(\mathrm{a})$ and effect of $\mathrm{Tf}_{2} \mathrm{~N}^{-}$concentration in DCE (b) on the number of coordinated water molecules $\left(n_{\mathrm{H}_{2} \mathrm{O}}\right)$ of the Eu(tta) chelate. (a) $\mathrm{Tf}_{2} \mathrm{~N}^{-}$concentration in the $\left[\mathrm{C}_{2} \mathrm{mim}\right]\left[\mathrm{Tf}_{2} \mathrm{~N}, \mathrm{ClO}_{4}\right]$ solution was kept constant at $0.50 \mathrm{~mol} \mathrm{dm}{ }^{-3}$ and (b) the $\left.\left[\mathrm{C}_{4} \mathrm{mim}_{[}\right] \mathrm{Tf}_{2} \mathrm{~N}\right]-\mathrm{DCE}$ solution was saturated with water. The error bars represent the standard deviation of $n_{\mathrm{H}_{2} \mathrm{O}}$. Concentration of $\left[\mathrm{Eu}(\mathrm{tta})_{3}\left(\mathrm{H}_{2} \mathrm{O}\right)_{3}\right]$ was $1.0 \times$ $10^{-4} \mathrm{~mol} \mathrm{dm}^{-3}$.

solvents of DCE with more than $3.4 \times 10^{-2}$ mol dm ${ }^{-3}$ of $\mathrm{Tf}_{2} \mathrm{~N}^{-}$. This result reveals that the coordination ability of $\mathrm{Tf}_{2} \mathrm{~N}^{-}$to $\mathrm{Eu}(\mathrm{tta})_{3}$ is stronger than that of water in non-coordinating solvents in contrast to that of $\mathrm{Tf}_{2} \mathrm{~N}^{-}$to $\mathrm{Eu}^{3+}$ ion in ILs. ${ }^{35}$ Jensen et al., reported that the hydrated $\left[\mathrm{Eu}(\mathrm{tta})_{2}\left(\mathrm{H}_{2} \mathrm{O}\right)_{2}\right]^{+}$and dehydrated $\mathrm{Eu}(\mathrm{tta})_{3}$ chelates were extracted from the aqueous phase containing $1 \mathrm{~mol} \mathrm{dm}{ }^{-3} \mathrm{NaClO}_{4}$ into the IL, 1-butyl-3methylimidazolium nonafluoro-1-butanesulfonate $\left(\left[\mathrm{C}_{4} \mathrm{mim}\right]\right.$ [NfO]), phase. ${ }^{66}$ Since the IL phase contained $10 \mathrm{~mol} \mathrm{dm}^{-3} \mathrm{H}_{2} \mathrm{O}$ and $1.6-2.3 \mathrm{~mol} \mathrm{dm}^{-3} \mathrm{NfO}^{-}$anion which is more hydrophobic than the $\mathrm{Tf}_{2} \mathrm{~N}^{-}$anion, the hydrated chelate cation can be preferentially extracted by the ion-exchange of the IL component.

Assuming that three water molecules of $\left[\mathrm{Eu}(\mathrm{tta})_{3}\left(\mathrm{H}_{2} \mathrm{O}\right)_{3}\right]$ were released by the coordination of $m$ molecules of $\mathrm{Tf}_{2} \mathrm{~N}^{-}$in the mixed solvent, the following equation is derived:

$$
\begin{aligned}
{\left[\mathrm{Eu}(\mathrm{tta})_{3}\left(\mathrm{H}_{2} \mathrm{O}\right)_{3}\right]_{\text {mix }}+} & m \mathrm{Tf}_{2} \mathrm{~N}_{\text {mix }}{ }^{-} \rightleftharpoons \\
& {\left[\mathrm{Eu}(\mathrm{tta})_{3}\left(\mathrm{Tf}_{2} \mathrm{~N}\right)_{m}\right]_{\text {mix }}{ }^{m-}+3 \mathrm{H}_{2} \mathrm{O}_{\text {mix }}, }
\end{aligned}
$$

where the subscript mix denotes the mixed solvent. The adduct formation constant $\left(\beta_{\mathrm{s}, m}\right)$ with $\mathrm{Tf}_{2} \mathrm{~N}^{-}$can be represented as follows:

$$
\beta_{\mathrm{s}, m}=\frac{\left[\mathrm{Eu}(\mathrm{tta})_{3}\left(\mathrm{Tf}_{2} \mathrm{~N}\right)_{m}{ }^{m-}\right]_{\text {mix }}}{\left[\mathrm{Eu}(\mathrm{tta})_{3}\left(\mathrm{H}_{2} \mathrm{O}\right)_{3}\right]_{\text {mix }}\left[\mathrm{Tf}_{2} \mathrm{~N}^{-}\right]_{\text {mix }}{ }^{m}} .
$$

The concentrations of $\left[\mathrm{Eu}(\mathrm{tta})_{3}\left(\mathrm{Tf}_{2} \mathrm{~N}\right)\right]^{-},\left[\mathrm{Eu}(\mathrm{tta})_{3}\left(\mathrm{H}_{2} \mathrm{O}\right)_{3}\right]$, and $\mathrm{Tf}_{2} \mathrm{~N}^{-}$in the mixed solvent were calculated from the $n_{\mathrm{H}_{2} \mathrm{O}}$ value of $\mathrm{Eu}(\mathrm{tta})_{3}$ in DCE containing 1.0 and $3.0 \mathrm{vol} \%\left[\mathrm{C}_{4} \mathrm{mim}\right]\left[\mathrm{Tf}_{2} \mathrm{~N}\right]$, and the $\log \beta_{\mathrm{s}, 1}$ value was estimated to be 2.7 . The $\beta_{\mathrm{s}, 1}$ value obtained was dramatically higher than that of MIBK in chloroform $\left(\log \beta_{\mathrm{s}, 1}=0.9\right)$ and carbon tetrachloride $\left(\log \beta_{\mathrm{s}, 1}=1.6\right) .{ }^{67}$ The dissociated $\mathrm{Tf}_{2} \mathrm{~N}^{-}$in solutions effectively coordinates to $\left[\mathrm{Eu}(\mathrm{tta})_{3}\left(\mathrm{H}_{2} \mathrm{O}\right)_{3}\right]$ and displaces the coordinated water molecules. In the LLD systems, the solubility of $\mathrm{Eu}(\mathrm{tta})_{3}$ is enhanced in hydrophobic ILs by the formation of the hydrophobic anionic chelate resulting from the release of the coordinated water molecules of $\left[\mathrm{Eu}(\mathrm{tta})_{3}\left(\mathrm{H}_{2} \mathrm{O}\right)_{3}\right]$. Consequently, the coordination environment of $\mathrm{Eu}(\mathrm{III})$ chelates in ILs is quite different from that of Eu(III) ion. ${ }^{35}$

\section{ESI-MS of $\left[\mathrm{Eu}(\mathrm{tta})_{3}\left(\mathrm{H}_{2} \mathrm{O}\right)_{3}\right]$ in the presence of $\left[\mathrm{C}_{4} \mathrm{mim}\right]\left[\mathrm{Tf}_{2} \mathrm{~N}\right]$}

To confirm the formation of the adduct complex, $\left[\mathrm{Eu}(\mathrm{tta})_{3}\left(\mathrm{Tf}_{2}\right.\right.$ $\mathrm{N})]^{-}$, in the presence of $\left[\mathrm{C}_{4} \mathrm{mim}\right]\left[\mathrm{Tf}_{2} \mathrm{~N}\right]$, negative ion ESI-MS was undertaken with $\left[\mathrm{Eu}(\mathrm{tta})_{3}\left(\mathrm{H}_{2} \mathrm{O}\right)_{3}\right]$ dissolved in DCE containing 1.0 vol\% $\left[\mathrm{C}_{4} \mathrm{mim}\right]\left[\mathrm{Tf}_{2} \mathrm{~N}\right]$ serving as the sample solution. Fig. 5 shows the mass spectrum of the sample recorded just after 100fold dilution with pure DCE. The high resolution mass spectrum covered the $\mathrm{m} / \mathrm{z}$ range from 1093 to 1099 and the calculated mass spectrum for $\left[\mathrm{Eu}(\mathrm{tta})_{3}\left(\mathrm{Tf}_{2} \mathrm{~N}\right)\right]^{-}$is represented by the dotted line. The full mass spectrum was normalized using the intensity at $\mathrm{m} / \mathrm{z}$ of 280 . Three clearly distinguishable peaks were observed at $\mathrm{m} / \mathrm{z}$ of 280,699 , and 1096 , which corresponded to $\mathrm{Tf}_{2} \mathrm{~N}^{-},\left[\mathrm{C}_{4} \operatorname{mim}\left(\mathrm{Tf}_{2} \mathrm{~N}\right)_{2}\right]^{-}$, and $\left[\mathrm{Eu}(\mathrm{tta})_{3}\left(\mathrm{Tf}_{2} \mathrm{~N}\right)\right]^{-}$, respectively. The experimental $\mathrm{m} / \mathrm{z}$ and the intensity ratio were consistent with the theoretical values, indicating the existence of $\left[\mathrm{Eu}(\mathrm{tta})_{3}\left(\mathrm{Tf}_{2}\right.\right.$ $\mathrm{N})]^{-}$as a stable adduct.
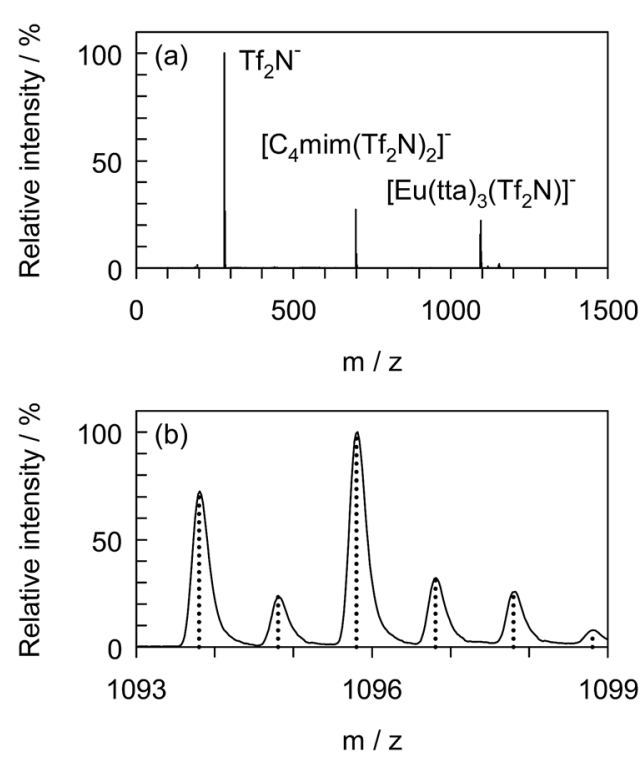

Fig. 5 Negative ion electrospray ionization mass spectrum of $\left[\mathrm{Eu}(\mathrm{tta})_{3}\left(\mathrm{H}_{2} \mathrm{O}\right)_{3}\right]$ dissolved in DCE containing $\left[\mathrm{C}_{4}\right.$ mim] $\left[\mathrm{Tf}_{2} \mathrm{~N}\right]$ (a) and the high resolution mass spectrum (solid line) and the calculated mass spectrum (dotted line) for $\left[\mathrm{Eu}(\mathrm{tta})_{3}\left(\mathrm{Tf}_{2} \mathrm{~N}\right)\right]^{-}$(b). Sample, $3.0 \times 10^{-4} \mathrm{~mol}$ $\mathrm{dm}^{-3}\left[\mathrm{Eu}(\mathrm{tta})_{3}\left(\mathrm{H}_{2} \mathrm{O}\right)_{3}\right], 3.4 \times 10^{-4} \mathrm{~mol} \mathrm{dm}^{-3}\left[\mathrm{C}_{4} \mathrm{mim}\right]\left[\mathrm{Tf}_{2} \mathrm{~N}\right]$. 


\section{Conclusions}

The special role of the $\mathrm{Tf}_{2} \mathrm{~N}^{-}$anions in the IL-water distribution of Eu(III)-tta chelates was elucidated in this paper. The equilibrium constants, $K_{\mathrm{ex}, 3}$ and $K_{\mathrm{ex}, 4}^{\prime}$ for the distribution of Eu(tta) $)_{3}$ and $\mathrm{Eu}(\mathrm{tta})_{4}{ }^{-}$, respectively, depended on the hydrophobicities of the ILs. The former were attributed only to the distribution constant of $\mathrm{Eu}(\mathrm{tta})_{3}\left(K_{\mathrm{D}, \mathrm{M}}\right)$ while the latter were also affected by the solubility product of the IL in the aqueous phase. The $K_{\mathrm{D}, \mathrm{M}}$ values in $\left[\mathrm{C}_{n} \mathrm{mim}\right]\left[\mathrm{Tf}_{2} \mathrm{~N}\right]$ were significantly enhanced by the specific solvation effect. The TRLFS study indicated that such specific solvation effect in ILs was caused by the replacement of the coordinated water molecules of $\left[\mathrm{Eu}(\mathrm{tta})_{3}\left(\mathrm{H}_{2} \mathrm{O}\right)_{3}\right]$ with $\mathrm{Tf}_{2} \mathrm{~N}^{-}$. The coordination ability of $\mathrm{Tf}_{2} \mathrm{~N}^{-}$toward $\left[\mathrm{Eu}(\mathrm{tta})_{3}\left(\mathrm{H}_{2} \mathrm{O}\right)_{3}\right]$ was confirmed in DCE. Furthermore, a most probable adduct species, $\left[\mathrm{Eu}(\mathrm{tta})_{3}\left(\mathrm{Tf}_{2} \mathrm{~N}\right)\right]^{-}$, was found by ESI-MS. Accordingly, the $\mathrm{Eu}(\mathrm{III})$ chelates can be present as IL components such as $\left[\mathrm{Eu}(\mathrm{tta})_{3}\left(\mathrm{Tf}_{2} \mathrm{~N}\right)\right]^{-} \cdot \mathrm{C}_{n} \mathrm{mim}^{+}$and $\mathrm{Eu}(\mathrm{tta})_{4}{ }^{-} \cdot \mathrm{C}_{n} \mathrm{mim}^{+}$in the ILs. In LLD, the hydrophobic metal chelate is effectively formed by the coordination of $\mathrm{Tf}_{2} \mathrm{~N}^{-}$in water-saturated ILs, resulting in the enhancement in the distribution constant of the neutral chelates. The knowledge obtained in this study can lead to the further progress in the development of IL distribution systems of metal ions.

\section{Acknowledgements}

The authors thank Dr Takumi Saito of The University of Tokyo for helping with TRLFS measurements. The Center for Instrumental Analysis at Ibaraki University is acknowledged for the elemental analysis and NMR measurements. This research was supported in part by JSPS KAKENHI Grant Numbers 26810078, 25620108 , and 25288064.

\section{Notes and references}

1 M. Petkovic, K. R. Seddon, L. P. N. Rebelo and C. S. Pereira, Chem. Soc. Rev., 2011, 40, 1383-1403.

2 M. D. Joshi and J. L. Anderson, RSC Adv., 2012, 2, 5470-5484.

3 T. D. Ho, C. Zhang, L. W. Hantao and J. L. Anderson, Anal. Chem., 2014, 86, 262-285.

4 A. Rehman and X. Zeng, RSC Adv., 2015, 5, 58371-58392.

5 D. R. MacFarlane, J. M. Pringle, P. C. Howlett and M. Forsyth, Phys. Chem. Chem. Phys., 2010, 12, 1659-1669.

6 H. Liu, Y. Liu and J. Li, Phys. Chem. Chem. Phys., 2010, 12, 1685-1697.

7 M. V. Fedorov and A. A. Kornyshev, Chem. Rev., 2014, 114, 2978-3036.

8 J. P. Hallett and T. Welton, Chem. Rev., 2011, 111, 3508-3576. 9 S. T. Keaveney, J. B. Harper and A. K. Croft, $R S C$ Adv., 2015, 5, 35709-35729.

10 P. N. Reddy, P. Padmaja, B. V. S. Reddy and G. Rambabu, RSC Adv., 2015, 5, 51035-51054.

11 J. Estager, J. D. Holbrey and M. Swadźba-Kwaśny, Chem. Soc. Rev., 2014, 43, 847-886.

12 E. Santos, J. Albo and A. Irabien, $R S C A d v ., 2014$, 4, 4000840018.
13 K. Goossens, K. Lava, C. W. Bielawski and K. Binnemans, Chem. Rev., 2016, 116, 4643-4807.

14 I. Billard, A. Ouadi and C. Gaillard, Anal. Bioanal. Chem., 2011, 400, 1555-1566.

15 N. Hirayama, Solvent Extr. Res. Dev., Jpn., 2011, 18, 1-14.

16 X. Sun, H. Luo and S. Dai, Chem. Rev., 2012, 112, 2100-2128.

17 F. Kubota, Y. Baba and M. Goto, Solvent Extr. Res. Dev., Jpn., 2012, 19, 17-28.

18 Z. Kolarik, Solvent Extr. Ion Exch., 2013, 31, 24-60.

19 C. Gaillard, M. Boltoeva, I. Billard, S. Georg, V. Mazan and A. Ouadi, RSC Adv., 2016, 6, 70141-70151.

20 K. Shimojo, K. Kurahashi and H. Naganawa, Dalton Trans., 2008, 5083-5088.

21 A. Rout and K. Binnemans, Dalton Trans., 2015, 44, 13791387.

22 S. A. Ansari, P. K. Mohapatra, V. Mazan and I. Billard, RSC Adv., 2015, 5, 35821-35829.

23 M. P. Jensen, J. Neuefeind, J. V. Beitz, S. Skanthakumar and L. Soderholm, J. Am. Chem. Soc., 2003, 125, 15466-15473.

24 K. Kidani, N. Hirayama and H. Imura, Anal. Sci., 2008, 24, 1251-1254.

25 K. Shimojo, H. Okamura, N. Hirayama, S. Umetani, H. Imura and H. Naganawa, Dalton Trans., 2009, 4850-4852.

26 H. Okamura, N. Hirayama, K. Morita, K. Shimojo, H. Naganawa and H. Imura, Anal. Sci., 2010, 26, 607-611.

27 K. Kidani and H. Imura, Talanta, 2010, 83, 299-304.

28 H. Okamura, H. Sakae, K. Kidani, N. Hirayama, N. Aoyagi, T. Saito, K. Shimojo, H. Naganawa and H. Imura, Polyhedron, 2012, 31, 748-753.

29 H. Okamura, A. Ikeda-Ohno, T. Saito, N. Aoyagi, H. Naganawa, N. Hirayama, S. Umetani, H. Imura and K. Shimojo, Anal. Chem., 2012, 84, 9332-9339.

30 H. Okamura, H. Takagi, T. Isomura, K. Morita, H. Nagatani and H. Imura, Anal. Sci., 2014, 30, 323-325.

31 M. Atanassova and V. Kurteva, RSC Adv., 2016, 6, 1130311324.

32 S. Stumpf, I. Billard, C. Gaillard, P. J. Panak and K. Dardenne, Radiochim. Acta, 2008, 96, 1-10.

33 J.-C. G. Bünzli, Chem. Rev., 2010, 110, 2729-2755.

34 R. N. Collins, T. Saito, N. Aoyagi, T. E. Payne, T. Kimura and T. D. Waite, J. Environ. Qual., 2011, 40, 731-741.

35 A. Brandner, T. Kitahara, N. Beare, C. Lin, M. T. Berry and P. S. May, Inorg. Chem., 2011, 50, 6509-6520.

36 P. Thakur, J. L. Conca, C. J. Dodge, A. J. Francis and G. R. Choppin, Radiochim. Acta, 2013, 101, 221-232.

37 S. A. Ansari, L. Liu, P. D. Dau, J. K. Gibson and L. Rao, RSC Adv., 2014, 4, 37988-37991.

38 S. A. Ansari, L. Liu and L. Rao, Dalton Trans., 2015, 44, 29072914.

39 S. A. Ansari, P. K. Mohapatra, W. Verboom, Z. Zhang, P. D. Dau, J. K. Gibson and L. Rao, Dalton Trans., 2015, 44, 6416-6422.

40 M. Atanassova, V. Kurteva and I. Dukov, RSC Adv., 2016, 6, 81250-81265.

41 W. D. Horrocks Jr and D. R. Sudnick, J. Am. Chem. Soc., 1979, 101, 334-340. 
42 R. M. Supkowski and W. D. Horrocks Jr, Inorg. Chim. Acta, 2002, 340, 44-48.

43 M. Schmeisser, P. Keil, J. Stierstorfer, A. König, T. M. Klapötke and R. van Eldik, Eur. J. Inorg. Chem., 2011, 4862-4868.

44 R. G. Charles and R. C. Ohlmann, J. Inorg. Nucl. Chem., 1965, 27, 255-259.

45 T. Sekine, Y. Hasegawa and N. Ihara, J. Inorg. Nucl. Chem., 1973, 35, 3968-3970.

46 K. Akiba, Bunseki Kagaku, 1972, 21, 1630-1636.

47 K. Akiba and T. Kanno, J. Inorg. Nucl. Chem., 1980, 42, 273276.

48 T. Wakabayashi, K. Takaizumi, K. Seto, N. Suzuki and K. Akiba, Bull. Chem. Soc. Jpn., 1968, 41, 1854-1858.

49 Y. Kitatsuji, Y. Meguro, Z. Yoshida, T. Yamamoto and K. Nishizawa, Solvent Extr. Ion Exch., 1995, 13, 289-300.

50 M. G. Freire, P. J. Carvalho, R. L. Gardas, I. M. Marrucho, L. M. N. B. F. Santos and J. A. P. Coutinho, J. Phys. Chem. $B, 2008,112,1604-1610$.

51 H. Imura and N. Suzuki, J. Radioanal. Nucl. Chem., 1985, 88, 63-73.

52 H. Imura and N. Suzuki, Talanta, 1985, 32, 785-790.

53 M. A. A. Rocha, C. F. R. A. C. Lima, L. R. Gomes, B. Schröder, J. A. P. Coutinho, I. M. Marrucho, J. M. S. S. Esperança, L. P. N. Rebelo, K. Shimizu, J. N. C. Lopes and L. M. N. B. F. Santos, J. Phys. Chem. B, 2011, 115, 1091910926.

54 H. Shirota, T. Mandai, H. Fukazawa and T. Kato, J. Chem. Eng. Data, 2011, 56, 2453-2459.
55 C. Kolbeck, J. Lehmann, K. R. J. Lovelock, T. Cremer, N. Paape, P. Wasserscheid, A. P. Fröba, F. Maier and H.-P. Steinrück, J. Phys. Chem. B, 2010, 114, 17025-17036.

56 T. Wakahayashi, S. Oki, T. Omori and N. Suzuki, J. Inorg. Nucl. Chem., 1964, 26, 2255-2264.

57 E. M. Larsen, G. Terry and J. Leddy, J. Am. Chem. Soc., 1953, 75, 5107-5111.

58 T. Omori, T. Wakahayashi, S. Oki and N. Suzuki, J. Inorg. Nucl. Chem., 1964, 26, 2265-2270.

59 N. Suzuki, K. Akiba and T. kanno, Anal. Chim. Acta, 1968, 43, 311-320.

60 G. F. de Sá, O. L. Malta, C. d. M. Donegá, A. M. Simas, R. L. Longo, P. A. Santa-Cruz and E. F. da Silva Jr, Coord. Chem. Rev., 2000, 196, 165-195.

61 L. D. Carlos, R. A. S. Ferreira, V. d. Z. Bermudez and S. J. L. Ribeiro, Adv. Mater., 2009, 21, 509-534.

62 M. Schmeisser, P. Illner, R. Puchta, A. Zahl and R. van Eldik, Chem.-Eur. J., 2012, 18, 10969-10982.

63 Y. Marcus, The Properties of Solvents, Wiley Series in Solution Chemistry, John Wiley \& Sons Ltd, Chichester, England, 1998, vol. 4.

64 J. Foropoulos Jr and D. D. DesMarteau, Inorg. Chem., 1984, 23, 3720-3723.

65 E. M. Arnett and C. Y. Wu, J. Am. Chem. Soc., 1962, 84, 16801684.

66 M. P. Jensen, M. Borkowski, I. Laszak, J. V. Beitz, P. G. Rickert and M. L. Dietz, Sep. Sci. Technol., 2012, 47, 233-243.

67 T. Sekine and D. Dyrssen, J. Inorg. Nucl. Chem., 1967, 29, 1457-1473. 